\title{
Synthesis of gold nanoparticles by laser ablation on porous silicon for sensing $\mathrm{CO}_{2}$ gas
}

\author{
Uday Muhsin Nayef ${ }^{1}$ and Intisar Mohammed Khudhair ${ }^{2}$ \\ ${ }^{1}$ Department of Applied Science, University of Technology, Baghdad, Iraq \\ ${ }^{2}$ Ministry of Sciences and Technology, Iraq \\ E-mail: unayef@yahoo.com
}

\begin{abstract}
In this research, porous silicon (PS) prepared by anodization etching on surface of single crystalline p-type $\mathrm{Si}$ wafer, then Gold nanoparticle (AuNPs) prepared by pulsed laser ablation in liquid. NPs deposited on PS layer by drop casting. The morphology of PS, AuNPs and AuNPs/PS samples were examined by AFM. The crystallization of this sample was characterized by X-ray diffraction (XRD). The electrical properties and sensitivity to $\mathrm{CO}_{2}$ gas were investigated to $\mathrm{Al} / \mathrm{AuNPs} / \mathrm{PS} / \mathrm{c}-\mathrm{Si} / \mathrm{Al}$, we found that AuNPs plays crucial role to enhance this properties.
\end{abstract}

Key words

Porous silicon, gold nanoparticle, electrical properties, gas sensing.

Article info.

Received: May. 2017

Accepted: Jul. 2017

Published: Mar. 2018

$$
\begin{aligned}
& \text { تحضير دقائق الذهب الناتوية بالاز الة الليزرية على السليكون المسامي للتحسس بغاز ثنائي } \\
& \text { اوكسيا الكاربون } \\
& \text { عدي محسن نايف1و انتصار محمد خضير2 }
\end{aligned}
$$

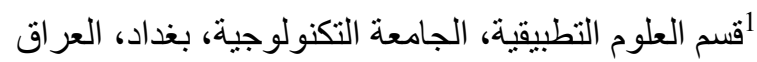

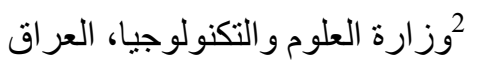

في هذا البحث تم تحضير السليكون المسامي بالتتميش الكهروكيميائي لشريحة السليكون نوع القابل وتم

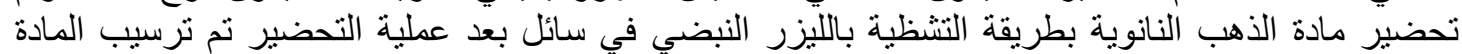

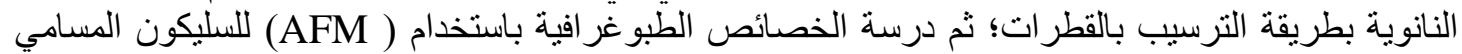

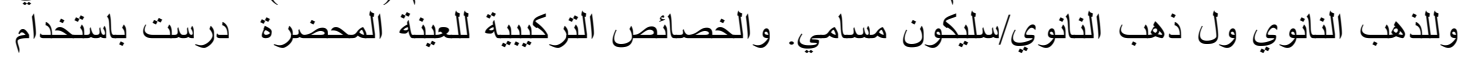
حيود الاشعة السينية. وكذللك درست الخصائص الكهربائية وتحسية العينات لغانية لغاز ثنائي اوكسيد الكاربون حيث وجد ان الذهب لعب دور جو هري بتحسين تللك الخصائص.

\section{Introduction}

With development of industries, different types of air pollutants are emitted from various sources to the atmosphere. Carbon dioxide $\left(\mathrm{CO}_{2}\right)$ gas is one of the colorless and odorless gases, which is produced by industrial processes. High concentration of $\mathrm{CO}_{2}$ gas effect in the earth's environment this can be harmful for humans and animal life. For this reason the requirement for $\mathrm{CO}_{2}$ measurement has increased with the risk of global warming and environmental awareness [1]. So it needs for gas sensor was reliable sensor to detect $\mathrm{CO}_{2}$ level in the air where $\mathrm{CO}_{2}$ is the one of the atmosphere composition [2, 3].

According to the definition of a gas sensor, given by the International 
Union of Pure and Applied Chemistry (IUPAC), "a chemical sensor is device that transforms chemical information, ranging from the consent ration of specific sample component into total composition analysis, to an analytically useful signal the chemical information, mentioned above, may originate from a chemical reaction of the analytic or from a physical property of the system investigated" [4].

PS discussed as an new material for chemical sensors and biosensors applications on account of its large specific area and its high reactivity, PS has unique properties such as direct bandgap, large surface area to volume ratio and the exactly like the single crystal structure as bulk [5, 6]. PS can be defined a silicon crystal having a network of avoid form when c-Si wafer is etched electrochemically in HF-Hydrofluoric acid based solution etching. The nanosized void in bulk $\mathrm{Si}$ create sponge like structure of pores and channel surrounded by a skeleton of c-Si nanowires [7, 8].

Surface of PS is spontaneous oxidation in ambient so we need to modify the PS surface so as to obtain stability of PS surface where this property is necessary to fabricated a stable porous silicon based device, so add noble metal nanoparticle (NMNP) such as $\mathrm{Au}$ and $\mathrm{Pt}$. the addition gold nanoparticle (AuNP) is play role important to obtain this stability [9, 10].

Gold nanoparticles (AuNPs) show one of the most remarkable area of present nanoscience and nanotechnology because the optical, magnetic, electrical and chemical properties all this properties depend on size and particle shape. AuNPs have special features like tunable shape and size, high absorption coefficient, high stability at different environment, non toxicity is environmental friendly so we can use in medicine, biotechnology and catalysis sensing [11-13]. The one important properties of AuNPs is named Surface Plasmon Resonance (SPR) because free electron which define it collective oscillation of the electron in conduction band with frequency in visible region. Plasmonic NP exhibit wide absorption band extended from UV-IR region of solar spectrum, the SPR is highly sensitive to morphology structure, dielectric constant to both metal and surrounding and refractive index of the surrounding medium [14]. AuNPs can made by laser ablation technique (pulse laser ablation in liquid), it can define this technique is physical process top-down to prepare nanoparticle by use the short pulses of laser energy focused on metal plate in liquid, the metal plate absorbs the energy and is vaporized the vaporized then condenses as nanoparticle [9]. The properties of this method is simple [10], quite easy, lowcost [15], do not require vacuum champers, very clean reliable method for generation the nanoparticles are free from contaminated [16].

In this paper AuNPs was deposited on PS layer to modified this layer where use AuNPs/PS/c-Si and PS/c-Si as gas sensor for detection carbon dioxide at room temperature.

\section{Experimental details}

PS layer was formed by anodization etching of (100)-oriented P-type Si wafers with resistivity $1.5-5 \Omega . \mathrm{cm}$ and $550 \pm 50 \mu \mathrm{m}$ thickness. $\mathrm{Al}$ was deposited on back side of $\mathrm{Si}$ wafer to enhanced distribution of current density in the anodization stage, before starting etching process we divided $\mathrm{Si}$ wafers into small pieces in dimension nearly of $2 \times 2 \mathrm{~cm}$. these samples were etched in the electrolyte consisted of Hydrofluoric acid (HF) and Ethanol $\left(\mathrm{C}_{2} \mathrm{H}_{5} \mathrm{OH}\right), \mathrm{HF}$ concentration in the solution is $20 \%$ in a current density $15 \mathrm{~mA} / \mathrm{cm}^{2}$ for $15 \mathrm{~min}$-time etching. 
AuNPs produced by laser ablation of gold target placed in bottom glass vessel containing $3 \mathrm{ml}$ of DDDWdouble distill deionized water (giving the production of ultrapure). the target was irradiated vertically by $\mathrm{Nd}: Y A G$ laser pulses $(1064 \mathrm{~nm})$ at different energy 160, 300, 460 and $600 \mathrm{~mJ}$ and the number pulses (500pulse) the laser is apply with lens (15 cm-focal length) is use to achieve high laser flounce, distance between target and lens is
$12 \mathrm{~cm}$, The experimental set up of pulsed laser ablation is shown in Fig.1. Then we deposited AuNPs on porous silicon by drop casting Fig. 2 shows sachem of hetrostructure AuNPs/PS/c$\mathrm{Si} / \mathrm{Al}$. the surface morphology was study by AFM, the crystallization characterized by XRD, surface chemical composition by FTIR, the electrical properties and gas sensing characterization to sample before and after deposition AuNPs.

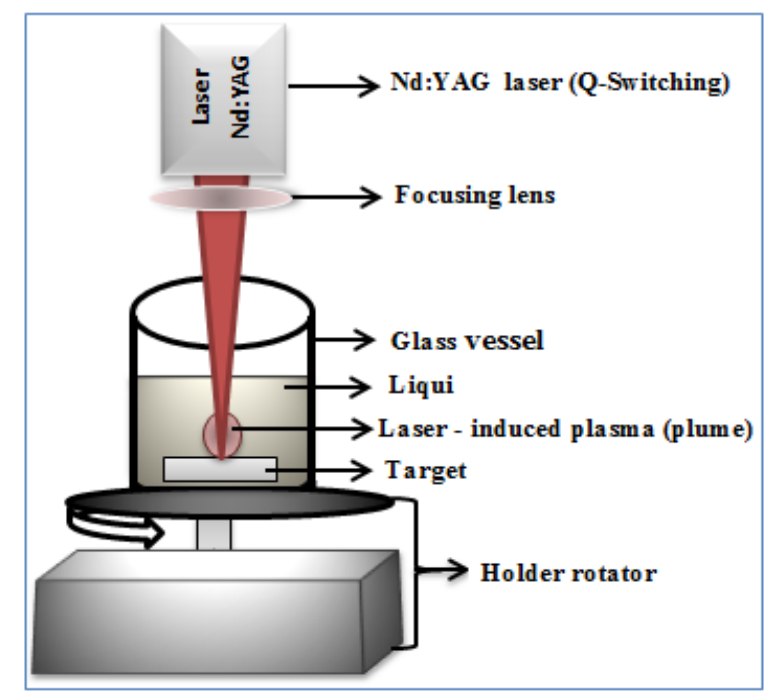

Fig.1: Schematic diagram of PLAL.

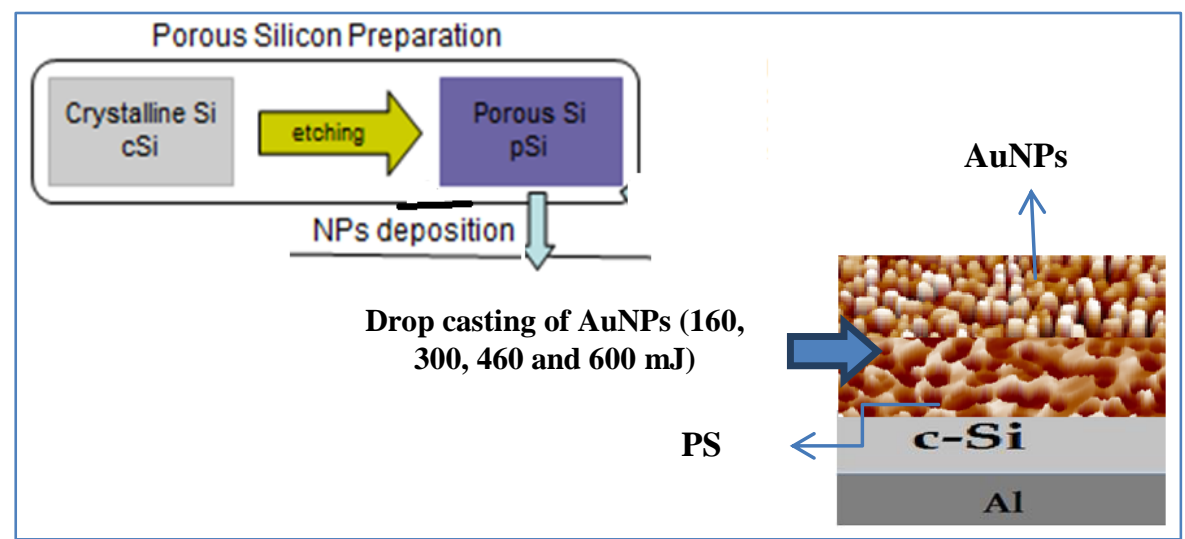

Fig. 2: Simple schematic diagram to AuNPs deposition on PS.

\section{Results and discussion Porous silicon (PS)}

Fig. 3 shows 3D image (AFM) of PS layer on p-type $\mathrm{Si}$ this image confirm the PS has sponge like structure with densely branched pore. In which the irregular and randomly distributed nanocrystalline $\mathrm{Si}$ pillars and voids over the entire surface can be observed. XRD studies showed distinct variation between the $\mathrm{p}-\mathrm{Si}$ surface and PS surface in Fig. 4. The different between bulk and PS the peak become broad due to in PS the ray 
diffraction from crystals with nanosize in the walls between pores, Consequently we can confirm that the PS layer remain crystalline. Fig. 5 shows the FTIR spectra of the PS, large specific area of PS and chemical properties of the surface has an effect on the electrical, optical and mechanical properties. The pore surface involves a high density of dangling bond of $\mathrm{Si}$ for original impurities (hydrogen and fluorine). Both electrolyte solutions which used for anodization etching and ambient air tack part to create this impurity. The transmittance peak at $611.43 \mathrm{~cm}^{-1} \mathrm{Si}-\mathrm{Si}$ stretching in $669.3 \mathrm{~cm}^{-1} \mathrm{Si}-\mathrm{H}$ wagging mode, $842.89 \mathrm{~cm}^{-1} \mathrm{Si}-\mathrm{O}$ bend in O-Si-O [17].

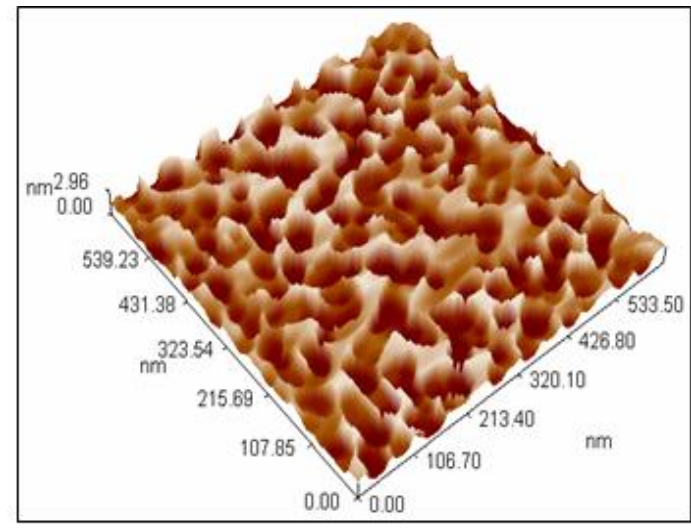

Fig. 3: 3D AFM image of PS layer at current density-15 $\mathrm{mA} / \mathrm{cm}^{2}$, etching time $15 \mathrm{~min}$ and $\mathrm{HF}_{c} 20 \%$.
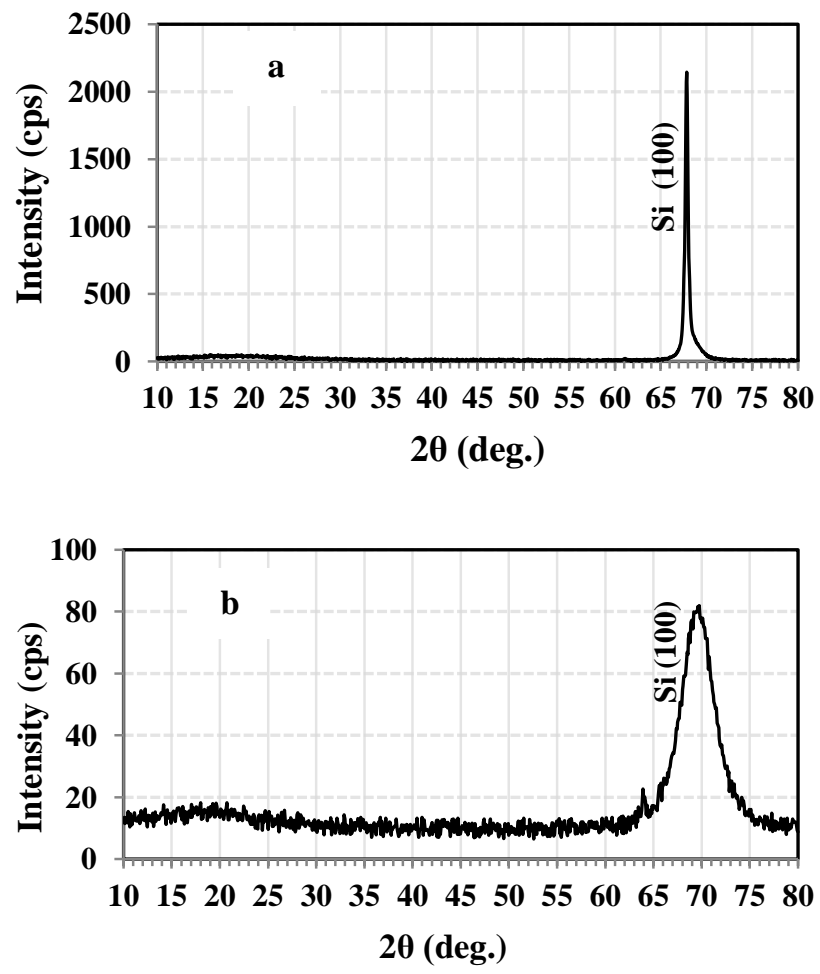

Fig. 4: XRD for (a) bulk Si and (b) PS layer. 


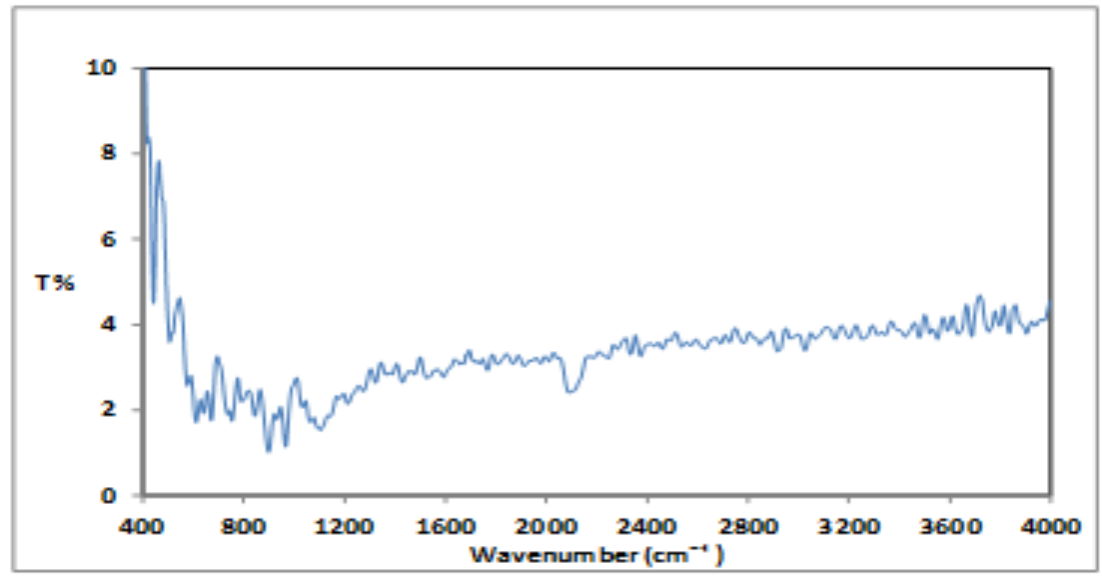

Fig. 5: FTIR transmittance spectrum of PS layer.

\section{Gold nanoparticle (AuNPs)}

Fig. 6 shows the absorption spectra of AuNPs in the suspension prepared with different laser energy 160, 300, 460 and $600 \mathrm{~mJ}$, the number of applied pulses 500 pulses and the wavelength $1064 \mathrm{~nm}$. The peak absorption is located at $512-517 \mathrm{~nm}$, that indicated the surface Plasmon resonance (SPR) for AuNPs where SPR depended on the size-shape of nanoparticle. The single peak is confirmed that the NPs present in the solution is spherical in shape and non-aggregated [18, 19]. When laser energy increases the intensity of the absorption spectra is increase because of increase the concentration of NPs, the absorbance depends on concentration of suspension [20], but at $460 \mathrm{~mJ}$ the ablation efficiency decrease due to the shielding effect when laser interact with solid surface the temperature of solid increase leading to melting and evaporation happen plasma the part of laser absorbed in plasma so the laser energy reaching the target reduce that called plasma shielding [21]. When laser energy exceeds $460 \mathrm{~mJ}$ the concentration begins increase so the absorption increases.
From absorption spectra it can be calculate the value of energy band gap we found this value decrease from $2.13 \mathrm{eV}$ at $160 \mathrm{~mJ}$ to $2.10 \mathrm{eV}$ at $600 \mathrm{~mJ}$ when laser energy increase because the particle size of AuNPs increase, see Fig. 7. Fig.8 shows AFM, 3D image for drop of the solution contain gold nanoparticle deposit on slide of glass the solution is prepared at $160 \mathrm{~mJ}$ and $600 \mathrm{~mJ}$ laser energy. the AFM image is confirm finding AuNps with spherical shape and different average size (less than $100 \mathrm{~nm}$ ) where the average particle size was increased from $(56.86 \mathrm{~nm}$ for $160 \mathrm{~mJ})$ to $(76.91 \mathrm{~nm}$ for $600 \mathrm{~mJ}$ ) this mean the particle size increase with increasing laser energy We can explain that the found small fragment such as AuNPs dispersed in solution the nanoparticle grow by attracting these small fragment. The fragmentation increase with increasing the laser energy [22]. It's worth mention if the size of NPs increase the SPR shifted toward larger wavelength see Table 1, from the image can see the AuNPs is uniform, homogenous and ligned vertically. 
Table 1: Effect of different laser energy on Uv-Vis peak and wavelength.

\begin{tabular}{|c|c|c|c|c|}
\hline Laser energy mJ & 160 & 300 & 460 & 600 \\
\hline $\begin{array}{c}\text { Uv-Vis Absorp. peak } \\
\text { intensity }\end{array}$ & 0.64 & 0.65 & 0.466 & 0.735 \\
\hline Wavelength nm & 512 & 515 & 514 & 517 \\
\hline
\end{tabular}

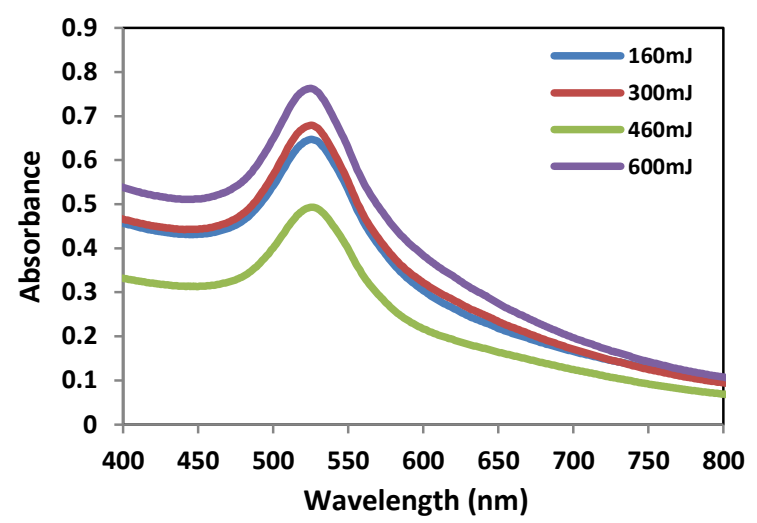

Fig. 6: Absorbance spectra of AuNPs produce at different laser energy.
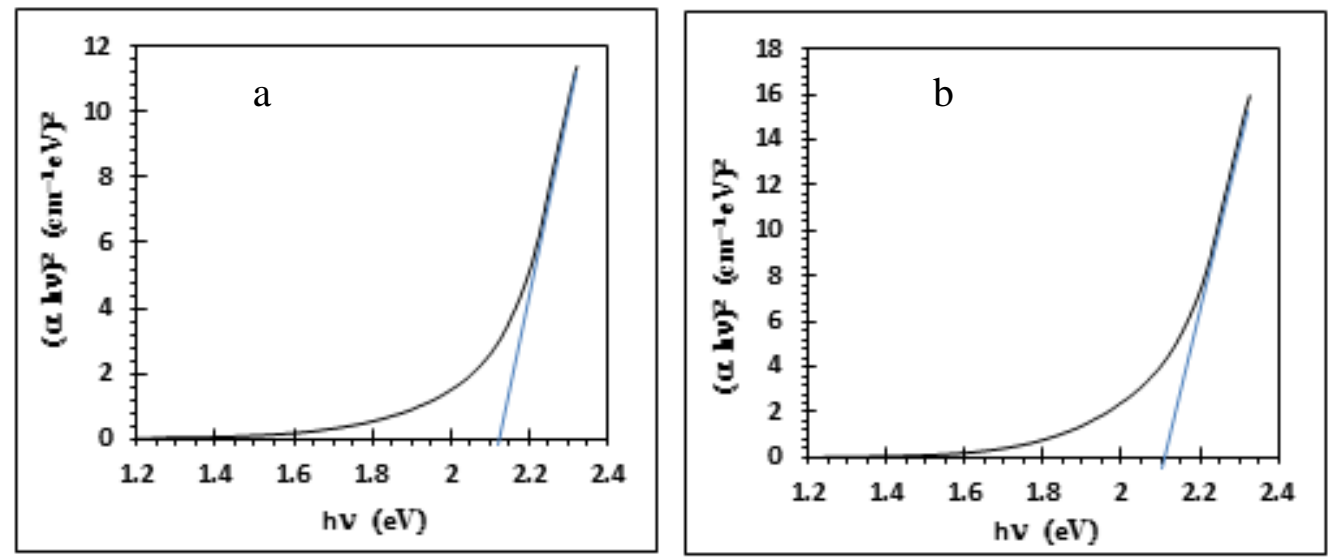

Fig. 7: The optical energy bandgap for the AuNPs prepared at different laser energy, a: $60 \mathrm{~mJ}$ and b: $600 \mathrm{~mJ}$.
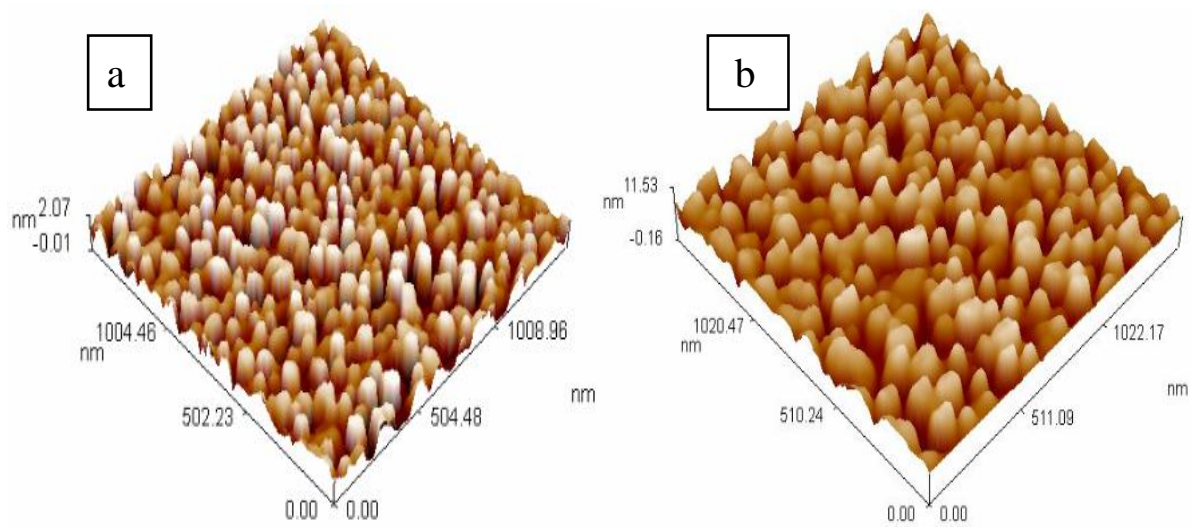

Fig. 8: 3D AFM image of AuNPs prepared at different laser energy, a: $160 \mathrm{~mJ}$ and b: $600 \mathrm{~mJ}$. 


\section{Properties of AuNPs on PS}

Fig. 9 shows AFM for AuNPs deposition on PS, this image appear the pores is full with colloids of AuNPs. The morphology of substrate at $600 \mathrm{~mJ}$ has larger pore compared with at $160 \mathrm{~mJ}$ because the particle size of AuNPs at $600 \mathrm{~mJ}$ is larger that lead to expand of pore size PS.

X-ray diffraction of the hetrostructure in Fig. 10 confirmed the formation of crystalline AuNPs during the laser ablation $\mathrm{Au}$ oxide nanoparticle produce in the water solution the main peak of $\mathrm{Au}$ oxide phase at $2 \Theta=32.68^{\circ}(311), 61.44^{\circ}(220)$ and PS $\sim 68^{\circ}$ (100).

Fig. 11 shows FTIR of this composite absorption band like peak in the region $3062 \mathrm{~cm}^{-1}$ which is attributed to $\mathrm{Si}-\mathrm{Au}, 2364 \mathrm{~cm}^{-1}$ for $\mathrm{Si}-\mathrm{H}-\mathrm{O}_{3}$ stretch, $1645 \mathrm{~cm}^{-1}$ attributed to $\mathrm{CO}, 1045 \mathrm{~cm}^{-1}$ for $\mathrm{Si}-\mathrm{O}, \mathrm{Si}-\mathrm{H}$ wagging at $682 \mathrm{~cm}^{-1}$. Found of these chemical group on $\mathrm{Au}$ particle surface indicated they found of $\mathrm{Au}$ oxide compound $\left(\mathrm{Au}_{2} \mathrm{O}_{3}=581 \mathrm{~cm}^{-1}\right)$ these compounds as result chemical reaction between highly excited ejected Au (an atoms, ions and clusters) with Oxygen atom in water "Au atoms bond break by laser energy and then recombine again through the cooling process of plasma during recombination processes some $\mathrm{Au}$ atom bond with oxygen atom and $\mathrm{Au}$ oxide molecules are formed" [23].

Fig. 12 shows the dark I-V characteristics in forward and reverse direction of $\mathrm{Al} / \mathrm{AuNPs} / \mathrm{PS} / \mathrm{c}-\mathrm{Si} / \mathrm{Al}$ and $\mathrm{Al} / \mathrm{PS} / \mathrm{c}-\mathrm{Si} / \mathrm{Al}$. from the fig found the forward current increase after embedding AuNPs. Current increase by increase voltage because the small bandgap of AuNPs by acting voltage enough energy to excite the electron from valance band to conduction band and left holes in valance band where due to increase the current in other words because schottky junction between AuNPs and PS layer by increasing the voltage the resistance junction decrease thus the current increase. As the concentration of AuNPs increase the resistivity of PS layer decrease gradually because the nanopores become filled with AuNPs that lead to increase the current [24].

The sensor sensitivity (S) of device is measure by the following formula: $S=([(I g-I o) / I 0] \times 100 \%)$ where $I_{g}$ is the current at $\mathrm{CO}_{2}$ gas and $I_{o}$ is the current at [25]. From Fig. 13a observed the sensitivity of AuNPs/PS increase when exposed to $\mathrm{CO}_{2}$ when AuNPs adsorbed $\mathrm{CO}_{2}$ the depletion layer between the AuNPs and porous silicon is become smaller because the free carrier which increase when adsorbed $\mathrm{CO}_{2}$ so the resistivity become smaller this mean the current is increase, from fig we notice the sensitivity is increase until reach maximum value at $5 \mathrm{~V}$ then decrease, for bias voltage higher than 5 $V$ that indicating the saturation of $\mathrm{CO}_{2}$ molecule adsorption at the structure surface. Also we can see from Fig. $13 \mathrm{~b}$ the $I-V$ characteristic of the sandwich device Al/AuNPs/PS/c-Si/Al for AuNPs prepare under different laser energy160, 300 and $600 \mathrm{~mJ}$ on PS layers before and after exposure $\mathrm{CO}_{2}$ gas. An increase the current flow is notice for all samples after exposed to $\mathrm{CO}_{2}$ gas, this mean increase the number of charge carrier after exposure, this effect can be attributed to generation acceptor level by $\mathrm{CO}_{2}$ molecule when adsorbed near the band edge of AuNPs causes the Fermi level to move towards the valance band, therefore the conductivity of AuNPs is increase $\mathrm{CO}_{2}$ act as acceptor center [25]. 


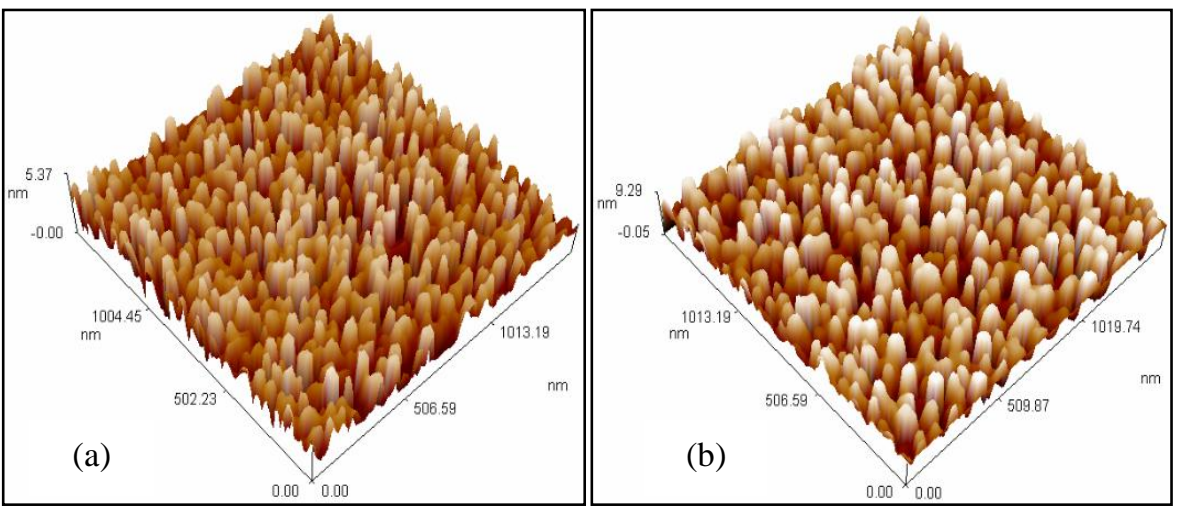

Fig. 9: AFM image of AuNPs /PS/c-Si /Al (a) AuNPs at $160 \mathrm{~mJ}$ and (b) AuNPs at $600 \mathrm{~mJ}$.

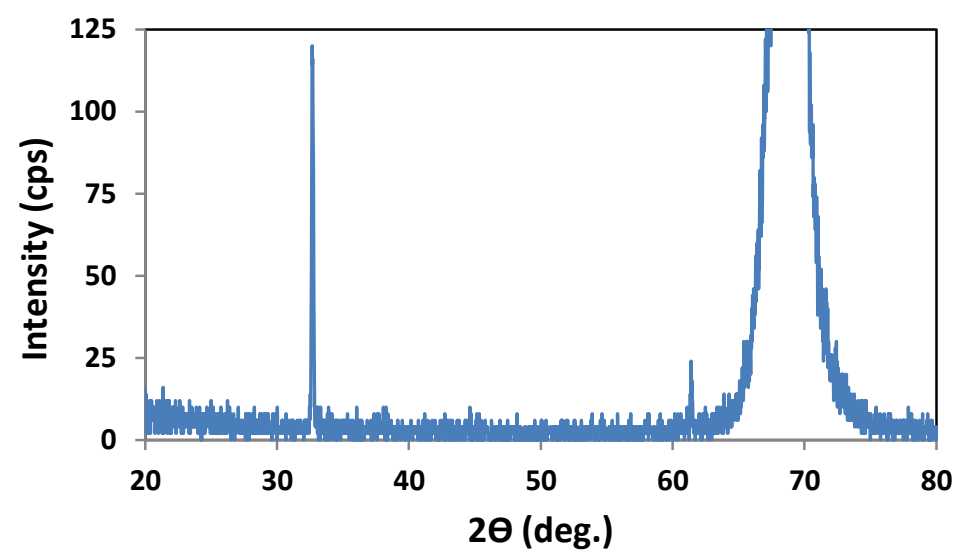

Fig.10: XRD of AuNPs/PS/c-Si /Al.

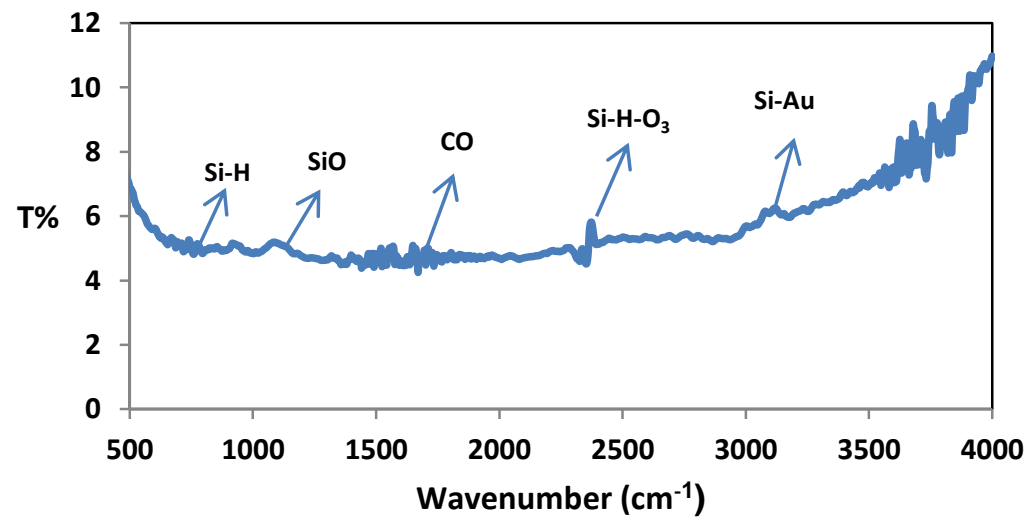

Fig. 11: FTIR spectrum of AuNPs /PS/c-Si when AuNPs prepare at $600 \mathrm{~mJ}$. 


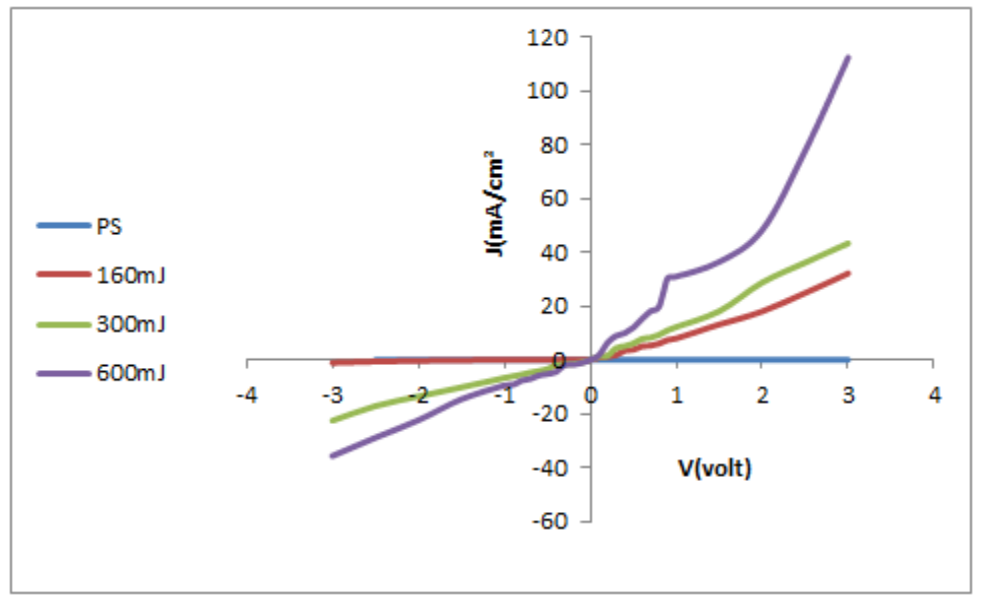

Fig. 12: The I-V characteristics of Al/AuNPs /PS/c-Si /Al when AuNPs prepare at different laser ablation.
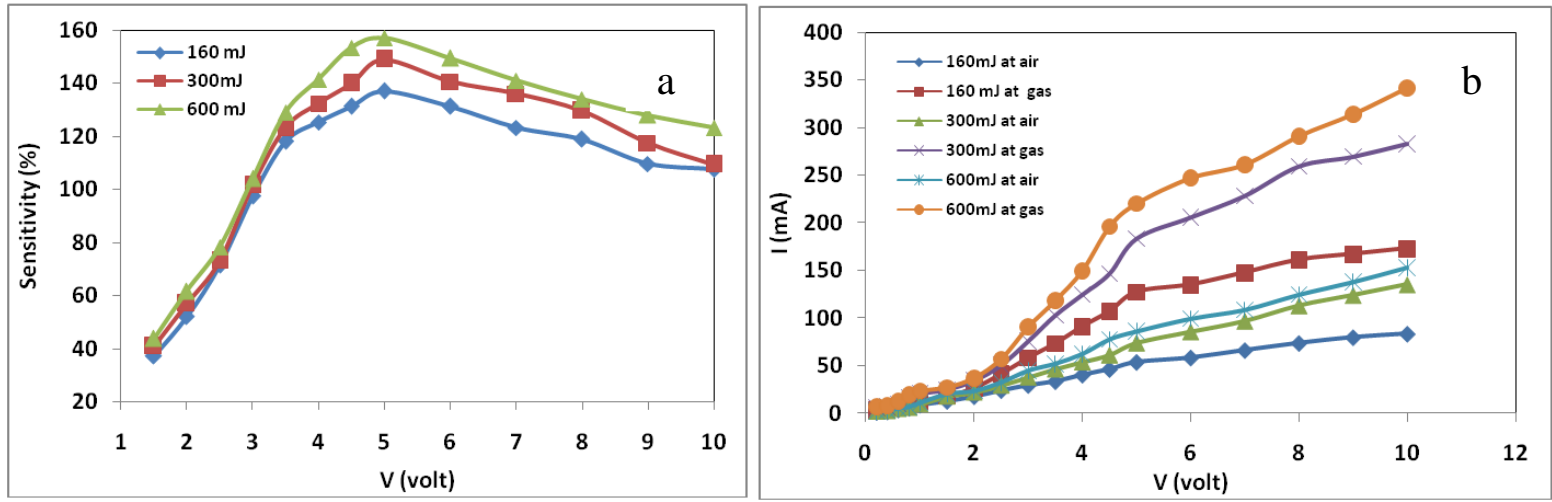

Fig. 13: a: The sensitivity of Al/AuNPs/PS/c-Si /Al. b: I-V characteristic for Al/AuNPs/PS/c-Si /Al before and after exposed to gas.

\section{Conclusions}

Prepared PS layer by electrochemical etching method, found by AFM investigation the Ps layer is homogeneous and the XRD confirm crystallization structure, use PLAl to prepare AuNPs, this NP was characterized by spherical shape, and found the particle size increase with increase the laser energy when deposit it on PS layer by drop casting the electrical properties and sensitivity is modified larger compared with PS layer alone.

\section{References}

[1] M. Ehsani, M. Hamidon, A. Toudeshki, M. Abadi, IEEE Sensors Journal, 16, 15 (2016) 1-7.
[2] G. Cadena, J. Riu, F. Rus, Journal the Royal Society of Chemistry, 132, 11 (2007) 1083-1099.

[3] C. Chiang, K. Ting Tsai, Y. Huan Lee, H. Wei Lin, Y. Lung Yang, C. Chung Shin, C. Yulin, H. Anjeng, Y. Hsuan Weng, Y. Yi Cheng, K. Chuan Ho, Ch. Au Dai, Microelectronic Engineering, 111 (2013) 409-415.

[4] A.Umar and Y. Hahn, "Metal Oxide Nnanostructure and their Applications" Book, by American Scientific Publishers, CA, USA (2009). [5] M. Gholami, M. Bahar, M. A. raghi, Elixir Chem. Phys. Letter, 48 (2012) 9626-9628.

[6] H. Hadi, T. Abood, A. Mohi, M. Karim, World Scientific News, 67, 2 (2017) 149-160. 
[7] U. Nayef, M. Walled, International Journal of Basic \& Applied Sciences, 13, 2 (2013) 15-17.

[8] W. Badaiwi, Applied Physics Research, 7, 5 (2015) 1-12.

[9] M. Hosny, D. Wissem, H. Ikbel and E. Hatem, Sensors \& Transducers, 27 (2014) 202-208.

[10] J. Kanungo, Applied Surface Science, 256 (2010) 4231-4240.

[11] T. Linga, K. Abdul Razak, A. Abdul Aziz, American Institute of Physics, 1455 (2012) 219-224.

[12] J. Polte, The Royal Society of Chemistry, 17 (2015) 6809-6830.

[13] L. Gulina, A. Pchelkina, K. Nikolaev, D. Navolotskaya, S. Ermakov, V. Tolstoy, Review. Advance Material Science, 44 (2016) 46-53.

[14] S. Gezgin, A. Kepceoğlu, H. Kilıç, American Institute of Physics, 1815 (2017) 1-4.

[15] T. Sarah, M. Hashim, N. Ali, H. Yazid, R. Adnan, Nanoscale Research Letters, 8, 35 (2013) 1-6.

[16] M. Palma, B. Krishnan, G. Rodriguez, T. Roy, D. Avellaneda, S. Shaji, Journal of Nanomaterials, 2016 (2016) 1-12.
[16] J. Das, S. M. Hossain, S. Chakraborty, H. Saha, Sensors and Actuators, A 94 (2001) 44-52.

[18] J. Philippe, S. Poulin, A. Kabashin, E. Sacher, M. Meunier, J. Luong, Journal Physics Chem., B 108 (2004) 16864-16869.

[19] V. Amenoda and M. Menghett, Phys. Chem., 11(2009) 3805-3821.

[20] S. Dash, A. Sikder, B. Bag, International Journal of Nanomaterial and Biostructure, 3, 2 (2013) 42-46.

[21] O. Dammer, B. Slouf, M. Pfleger, Material Science and Engineering, 140, 3 (2007) 138-146.

[22] H. Imam, K. Elsayed, M. Ahmed, R. Ramdan, Optic and Photonic Journal, 2, 2 (2012) 73-84.

[23] N. Mirghassemzadeh, M. Ghamkhari, D. Dorranian, Soft Nanoscience Letters, 3 (2013) 101106.

[24] S. Basu, "CrystallineSilicon Properties and Uses", Book, by InTech Janeza Trdine 9, 51000 Rijeka, Croatia, 2011.

[25] M. Araghi and Z. Bisadi, The European Physical Journal Applied Physics, 58 (2012) 1-8. 